\title{
Computer and internet use among tertiary healthcare providers and trainees in a Nigerian public hospital
}

\author{
Ibrahim Taiwo ADELEKE ${ }^{1, ~ *, ~ M u n i r u ~ A d e r e m i ~ A S I R U ², ~ B e n s o n ~ M a c a u l a y ~ O W E G H O R O ~}$ \\ Ahmed Bolakale JIMOH ${ }^{1}$, Ameenah Muhammad NDANA ${ }^{4}$ \\ ${ }^{1}$ Department of Health Information, Federal Medical Centre, Bida NIGERIA \\ ${ }^{2}$ Department of Mathematics \& Statistics, Federal Polytechnic, Bida NIGERIA \\ ${ }^{3}$ Department of Library, Archive \& Information Studies, University of Ibadan NIGERIA \\ ${ }^{4}$ Department of Health Information Management, College of Health Technology, Minna NIGERIA
}

\section{Email address:}

ibratadeleke_aliseyin@yahoo.com (Adeleke I.), maasiru@yahoo.com (Asiru M.), bmoweghoro@gmail.com (Oweghoro B.), bolak58@yahoo.com (Jimoh A.), meenatndana@gmail.com (Ndana A.)

\section{To cite this article:}

Ibrahim Taiwo ADELEKE, Muniru Aderemi ASIRU, Benson Macaulay OWEGHORO, Ahmed Bolakale JIMOH, Ameenah Muhammad NDANA. Computer and Internet Use among Tertiary Healthcare Providers and Trainees in a Nigerian Public Hospital. American Journal of Health Research. Special Issue: Health Information Technology in Developing Nations: Challenges and Prospects Health Information Technology. Vol. 3, No. 1-1, 2015, pp. 1-10. doi: 10.11648/j.ajhr.s.2015030101.11

\begin{abstract}
The Nigerian healthcare system is characterized with paper-based health information management systems and grossly inadequate IT-skilled healthcare providers. Nonetheless, the emerging digitization and globalization has the potentials to speed up the transformation of the current healthcare systems and revolutionize the provider-consumer relationship between healthcare providers and their teeming patients. This cross-sectional study determined the utilization of computer and the Internet among healthcare providers and trainees in a Nigerian public hospital $(n=232)$. More than half $(112,52 \%)$ of the participants were females and the vast majority $(154,72.3 \%)$ were aged forty years or below with a Mean age of $35 \pm 9$ years. More than a third $(78,36.6 \%)$ of the participants had used the Internet for over three years and early exposure to computer use did significantly influence $\left(\chi_{2}=3.19 ; p=0.00\right)$ their current computer use. Updates on professional issues appeared the major reason $(98,46.0 \%)$ for searching the Internet and this was mostly accessed $(149,70.0 \%)$ through cell phone. Google Scholar was the most $(154,72.3 \%)$ deployed search engine and participants were often constrained $(93,43.7 \%)$ to use these technologies by inadequate time due to their busy schedules. For better appreciation of the technologies, participants solicited for further training in health IT. Healthcare providers and trainees at Federal Medical Centre, Bida have good disposition towards computer and Internet use especially to enhance their professional practice and to improve patient care quality. They overwhelmingly indicated interests for further ICT training in order to boost their sources of information for an improved healthcare practice. Any effort made to enrich their sources of information and to enhance their usability of these technologies would be worthwhile.
\end{abstract}

Keywords: Computerized Patients Records, Health Information Management, Health Information Technology, Internet, Medical Informatics, Personal Health Records, Developing Countries, Nigeria

\section{Introduction}

The computer is an important tool in the management of information because of the speed with which it processes information. It is the major information technology tool that has transformed information and data handling processes in all endeavours [1]. It has been adjudged [2] by both healthcare experts and consumers alike, as having critical roles to play in the transformation of healthcare services.
Wheatley [3] reported that the deployment of information technology in healthcare management has provided a mechanism for promoting greater reliability in healthcare quality. Computer now plays a vital role in packaging and delivery of health information and medical literatures [4]. Similarly, the Internet is visibly having the most historic influence on virtually all fields of endeavour due to its dynamic and far-reaching communication system [5] and the fact that information sources therein are increasing 
exponentially [6]. The Internet enables automated selection of relevant information and quality control, and it enables users to see what their peers or others with predefined relationships do [7]. According to Hurling et al [8], the evolution of the Internet has established patient-controlled health record which is accessible through the worldwide web. With this development, patients are able to identify which data element to be accessible to the requesting parties as a mark of health information security and medical confidentiality. In the same way, healthcare providers and hospital administrators have always believed that the technology capacity of computer and the Internet would protect patients' confidentiality [9-13]. For the protection of health information on the Internet, researchers $[14,10]$ recommended providers' self-regulation, consumer evaluation and punishment of erring providers.

Conversely, healthcare industry has been slower than other sectors such as business, banking and education in taking the advantage of computer technology especially, in developing countries [15]. In Nigeria for instance, healthcare system is characterized with paper-based health information management systems and grossly inadequate IT-skilled healthcare information managers [16]. In spite of this, the global relevance and importance of computer and the Internet for communication, information retrieval and support for healthcare service delivery, training and research cannot be overstated. In the same vein, accurate, promptly documented and regularly reviewed healthcare information is essential to healthcare delivery system [17]. This may not be possibly achieved without the use of computer and the Internet in processing healthcare information especially, in this hi-tech age [16]. Nowadays, healthcare consumers often seek healthcare information on the Internet [18], and they often rely on it as a major source of health information more than their physicians [19]. However, these patients still desire to discuss Internet-based health information with their healthcare providers [19]. This calls for information cognizance among major players in the industry. In the light of this, there is need for the providers to brace up and adopt ICT in their practice in order to enhance the emerging consumer-driven health information system such that will improve care process and outcome. Various studies [4, 2022] reported that ICT use has become advanced among healthcare providers, it has become one source of information for care process and there is observed high and widespread usage of computer and the Internet. However, other studies [23-25 and 16] reported hindered access to the Internet, underutilization of evidence-based sources such as computer and the Internet in the delivery of healthcare services and obvious IT-skill gaps among healthcare providers. Although enhancement of professionalism and improved healthcare quality are generally considered as the major factors for using the Internet in healthcare settings, studies have shown that various other reasons predispose individual healthcare provider's computer and Internet use. For instance, researchers [26-27 and 24] reported that providers were influenced to use these technologies in order to gain knowledge on how to avoid contracting diseases from the patients, awareness on disease outbreaks and to discover latest research on specific diseases. Similarly, researchers [28-30] have reported confidence to obtain answers, issuance of prescriptions, booking of appointments and the ability of the technology to access current health information to support evidence-based practice as reasons for using computer and the Internet.

On barriers to the use of these technologies, studies [26, 31-32, 16 and 24] identified inability to access foreign journals, lack of skills to use medical databases, workload, time constraints and source location from the hospital as some of the barriers. Others include; too much information on the Internet, lack of specificity, searching difficulties, inadequate ICT infrastructure, needs to acquire ICT and information seeking skills, lack of structure training, limited or hindered Internet access, relatively expensive nature of the Internet café and lack of current information materials on the Internet [33-34, 25 and 35].

\subsection{Aim of the Study}

Computer and the Internet are widely used in healthcare and medical practice, and it has made significant impacts on research, education and healthcare service delivery to the patients. However, very few studies have attempted to know the usage rate of these technologies for patients' care among healthcare professionals in Nigeria. Therefore, this present study sought to determine computer and the Internet use among healthcare professionals and trainees at Federal Medical Centre, Bida, Nigeria.

\section{Methods}

\subsection{Background to the Study Areas}

The study was carried out at Federal Medical Centre Bida (FMCB), Nigeria. The hospital was converted to a tertiary healthcare centre in 1997 having served as colonial and state government owned general hospitals for several decades. The hospital has twenty five medical and paramedical specialties and subspecialties, twenty weekly consultative clinics and has a bed complement of 200 . As a tertiary healthcare facility of more than one and a half decade, the hospital has treated more than a million patients as outpatients and has offered inpatient services to more than one hundred thousand clients. Health Information Management (HIM) students from College of Health Technology Minna who periodically undergo compulsory hospital-based professional training in the Department of Health Information of the hospital were recruited into the study. The College of Health Technology, Minna is one of the numerous higher institutions of learning owned by the Niger State Government and the institution trains diverse health professionals among who are HIM students.

\subsection{Study Design}

This is a cross-sectional study of the three key information-driven and information-intensive healthcare 
professional groups in the hospital. These are nurses, doctors and HIM professionals, including HIM students.

\subsection{Study Population}

Nurses: Nursing is a profession within the healthcare sector that focuses on the care of individuals, families and communities so they may attain, maintain, or recover optimal health and quality of life. As at the time of the study, 282 nurses were at the employment of FMCB. Doctors: Medical doctors are the key providers of healthcare services and are the major users of hospital information systems. A total number of 146 doctors work with FMCB. HIM professionals: There are 57 HIM professionals in the service of FMCB. Mainly, these categories of healthcare providers are dedicated to the effective management of patient health information and healthcare data needed to deliver high-quality treatment and care to the public and have leadership roles in healthcare information systems. HIM students: There were 98 HIM technicians in-training at the College of Health Technology, Minna Niger State as at the time of the study.

\subsection{Data Collection Tools}

The questionnaire was developed from review of literatures and modeled after two specific previous studies (Yeung et al, 2004; Ajuwon, 2006). The tool is divided into four basic sections as follow: section A contains four items on participants' basic demography; section B covers four items on the use of computers. Section $\mathrm{C}$ with six questions focuses utilization of the Internet, while the final part (section D) contains six items which determine how and why participants use the Internet. Data collection exercise took place between $17^{\text {th }}$ June and $2^{\text {nd }}$ August 2013.

\subsection{Sampling Technique and Sample Size}

The study deployed stratified random sampling method. From the study population above, the total number of professionals and trainees targeted were 583 which include; 282 nurses, 146 doctors, 98 HIM students and 57 HIM professionals. Online sample size calculation software (www.surveysystem.com/sscalc.htm) was used to compute the sample size. The computed sample size was 232 with a proportion of 111, 58, 40 and 23 for nurses, doctors, HIM students and HIM professionals respectively.

\subsection{Inclusion and Exclusion Criteria}

All HIM professionals below the CONHESS level of 6 were excluded from the study.

\subsection{Data Analysis and Management}

The statistical software SPSS V16.0 (2007) was used to analyze the data. Categorical data was expressed as proportions and percentages while continuous variables, were expressed as mean \pm standard deviation. Association between categorical variables was expressed using Chi square $\left(\chi^{2}\right)$ and test of statistical significance ( $p$-value) was set at $p=0.05$.

\subsection{Ethics}

Ethics approval to conduct this study was sought from the Hospital Research Ethics Committee of Federal Medical Centre, Bida. A clearly worded informed consent (Appendix I, page 1) was made available to the participants and the study detail was vividly explained to them with a view to obtaining their consent before the administration of questionnaire.

\section{Results}

\subsection{Response Rate}

Two hundred and thirteen $(91.8 \%)$ of the 232 questionnaires administered were completed and returned for analysis.

\subsection{Socio-Demographic Characteristics}

Table 1 below shows the demographic characteristics of the participants. More than half $(112,52 \%)$ of the participants were females and the vast majority $(154,72.3 \%)$ were forty years old or below, with a Mean age of $35 \pm 9$ years. Cross tabulation analysis further corroborated this that more than half $(59,57.3 \%)$ of nurses, majority $(34,72.3 \%)$ of doctors, most $(21,91.3 \%)$ HIM professionals and all (40, $100 \%)$ HIM students were aged forty years or below. Nurses alone constituted about half $(103,48.4 \%)$ of the participants.

Table 1. Socio-demographic characteristics of participants

\begin{tabular}{|c|c|c|}
\hline & Frequency & $\%$ \\
\hline \multicolumn{3}{|l|}{ Sex } \\
\hline Male & 101 & 47.4 \\
\hline \multirow[t]{2}{*}{ Female } & 112 & 52.6 \\
\hline & 213 & 100 \\
\hline \multicolumn{3}{|l|}{ Age group } \\
\hline Less than 21 years & 1 & 0.5 \\
\hline $21-30$ years & 77 & 36.2 \\
\hline $31-40$ years & 76 & 35.7 \\
\hline $41-50$ years & 53 & 24.9 \\
\hline \multirow[t]{2}{*}{$51-60$ years } & 6 & 2.8 \\
\hline & 213 & 100 \\
\hline \multicolumn{3}{|l|}{ Profession } \\
\hline Nursing & 103 & 48.4 \\
\hline Medicine \& Surgery & 47 & 22.1 \\
\hline HIM students & 40 & 18.8 \\
\hline \multirow[t]{2}{*}{ HIM professionals } & 23 & 10.8 \\
\hline & 213 & 100 \\
\hline \multicolumn{3}{|c|}{ Salary level (CONHESS/equivalent) } \\
\hline $13-15$ & 21 & 9.9 \\
\hline $9-12$ & 68 & 31.9 \\
\hline $6-8$ & 79 & 37.1 \\
\hline HIM students & 40 & 18.8 \\
\hline \multirow[t]{2}{*}{ No response } & 5 & 2.3 \\
\hline & 213 & 100 \\
\hline
\end{tabular}

\subsection{Relationship between Using Computer and the Internet}

Computer and the Internet are the two emerging technologies intertwined in the widely held information and 
communication technology (ICT). Although experience in computer had statistical significance $(\chi 2=3.43 ; p=0.00)$ on participants' frequency in utilization of the Internet, only a few $(20,13.1 \%)$ of those who had good computer experience used the Internet regularly.

\subsection{Impact of Users' Experience on Continuous Utilization of Computer and the Internet}

Of the 213 healthcare professionals in the study, Table 2 below shows that a little above half $(113,53.1 \%)$ of them had used computers for more than three years and about a quarter
$(51,23.9 \%)$ had used it for more than seven years. The majority $(38,74.5 \%)$ of those who had used computers for more than seven years used it daily in recent times. Likewise, half $(16,50.0 \%)$ of those participants (the $15.0 \%)$ who had used the Internet for more than seven years, used it daily. Generally, it is noteworthy to say that two-third (146, 66.7\%) of all participants used the Internet more than once a week. Previous exposure and utilization had strong statistical significance on recent and continuous use of computer $\left(\chi^{2}=\right.$ $3.19 ; p=0.00)$ and the Internet $\left(\chi^{2}=1.97 ; p=0.00\right)$.

Table 2. Experience in computer and Internet versus recent use

\begin{tabular}{|c|c|c|c|c|c|c|c|c|}
\hline & \multicolumn{6}{|c|}{ Recent use } & \multirow{2}{*}{$\begin{array}{l}\text { No } \\
\text { response }\end{array}$} & \multirow{2}{*}{ Total } \\
\hline & Everyday & More than once a week & Once a week & Less than once a week & Don't know & Never used & & \\
\hline \multicolumn{9}{|l|}{ Computer experience } \\
\hline Less than 6 months & 6 & 2 & 5 & 3 & 3 & 3 & 0 & 22 \\
\hline $6-12$ months & 8 & 7 & 2 & 6 & 0 & 1 & 0 & 24 \\
\hline $1-3$ years & 20 & 20 & 18 & 4 & 4 & 0 & 1 & 67 \\
\hline $4-6$ years & 20 & 8 & 4 & 0 & 2 & 1 & 0 & 35 \\
\hline Above 7 years & 38 & 7 & 5 & 1 & 0 & 0 & 0 & 51 \\
\hline $\begin{array}{l}\text { Never used computer } \\
\text { Internet experience }\end{array}$ & 0 & 0 & 0 & 0 & 0 & 13 & 0 & 13 \\
\hline Less than 6 months & 9 & 5 & 5 & 3 & 1 & 1 & 1 & 25 \\
\hline $6-12$ months & 8 & 11 & 6 & 4 & 1 & 0 & 0 & 30 \\
\hline $1-3$ years & 22 & 21 & 9 & 7 & 0 & 0 & 1 & 60 \\
\hline $4-6$ years & 23 & 16 & 4 & 0 & 2 & 1 & 0 & 46 \\
\hline Above 7 years & 16 & 11 & 3 & 1 & 0 & 1 & 0 & 32 \\
\hline \multicolumn{9}{|l|}{ Legend } \\
\hline \multirow[t]{2}{*}{ Indicator } & & & Value & & & & & \\
\hline & & & Computer & & Internet & & & \\
\hline$\chi^{2}$ & & & 3.19 & & 1.97 & & & \\
\hline$p$-value & & & 0.00 & & 0.00 & & & \\
\hline$\%>7$ years who used & & & 74.5 & & 50 & & & \\
\hline$\%<6$ months who use & daily & & 27.3 & & 36 & & & \\
\hline
\end{tabular}

Table 3. Experience in computer and internet use among professionals

\begin{tabular}{|c|c|c|c|c|c|}
\hline & \multicolumn{5}{|c|}{ Recent computer use } \\
\hline & Nursing & Medicine \& Surgery & HIM students & HIM & Total \\
\hline \multicolumn{6}{|l|}{ Computer experience } \\
\hline Less than 6 months & 9 & 1 & 9 & 3 & 22 \\
\hline 6 - 12 months & 11 & 1 & 8 & 4 & 24 \\
\hline $1-3$ years & 41 & 7 & 13 & 6 & 67 \\
\hline $4-6$ years & 19 & 11 & 3 & 2 & 35 \\
\hline Above 7 years & 13 & 27 & 4 & 7 & 51 \\
\hline Never used computer & 9 & 0 & 3 & 1 & 13 \\
\hline No response & 1 & 0 & 0 & 0 & 1 \\
\hline \multicolumn{6}{|l|}{ Internet experience } \\
\hline Less than 6 months & 15 & 1 & 5 & 4 & 25 \\
\hline $6-12$ months & 17 & 2 & 10 & 1 & 30 \\
\hline 1 - 3 years & 33 & 7 & 12 & 8 & 60 \\
\hline $4-6$ years & 19 & 17 & 6 & 4 & 46 \\
\hline Above 7 years & 9 & 18 & 1 & 4 & 32 \\
\hline Never used computer & 9 & 0 & 6 & 1 & 16 \\
\hline No response & 1 & 2 & 0 & 1 & 4 \\
\hline \multicolumn{6}{|l|}{ Legend } \\
\hline \multirow[t]{2}{*}{ Indicator } & & & & Value & \\
\hline & & & & Computer & Internet \\
\hline \multicolumn{4}{|l|}{$\chi^{2}$} & 67.79 & 57.92 \\
\hline \multicolumn{4}{|l|}{$p$-value } & 0.00 & 0.00 \\
\hline \multicolumn{4}{|c|}{$\%$ doctors with $>7$ years' experience } & 57.4 & 38.3 \\
\hline \multicolumn{4}{|c|}{$\%$ HIM students with $<6$ months experience } & 22.5 & 15 \\
\hline
\end{tabular}




\subsection{Various Platforms of Accessing the Internet}

Fig. 1 that follows, shows that the majority $(149,70.0 \%)$ of the participants used cell phone to access the Internet whereas, only a few of them $(14,6.6 \%)$ accessed the Internet through the local Internet services provided by the hospital management.

\subsection{Search Engines and Social Media}

The Internet is explored through many channels for diverse reasons. Google Scholar was the most (154, 72.3\%) deployed search engine among participants, and was closely followed by Facebook (140, 65.7\%). Others include YahooGroup (68, $31.9 \%)$ and MEDLINE/Pubmed (51, 23.9\%).

\subsection{Participants' Computer and Internet Use by Professions}

Computer and Internet use among professionals is categorically illustrated in Table 3 above. Nearly three in every five $(27,57.4 \%)$ of doctors were found to have used computers for more than seven years whereas only one-tenth $(4,10 \%)$ of HIM students had used it for the same number of years. In the same vein, about two-fifth $(78,36.6 \%)$ had used the Internet for more than three years with doctors leading by more than two-fifth $(35,44.9 \%)$ and HIM students, the least (7, 9.0\%). Incidentally, profession had strong statistical significance on computer $(\chi 2=67.79 ; p=.00)$ and Internet use $(\chi 2=57.92 ; p=.00)$. In addition, a discernible portion of the participants $(16,7.5 \%)$ had never used the Internet with nurses taking the highest portion $(9,56.3 \%)$ of these nonusers.

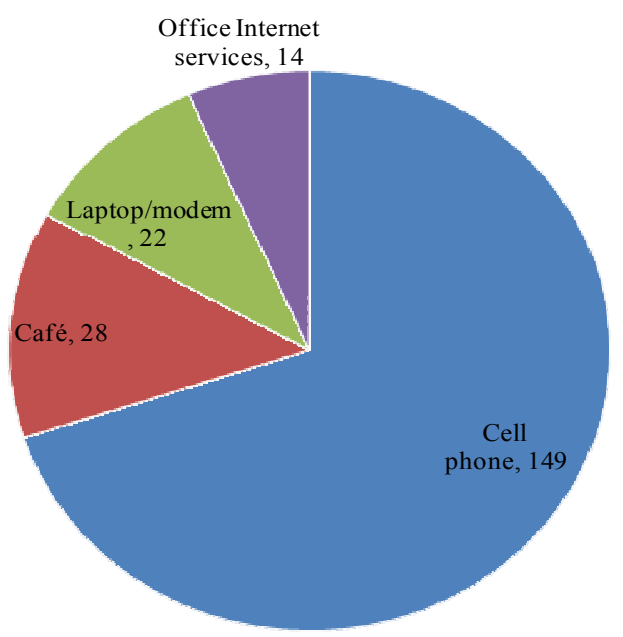

Figure 1. Platforms for accessing the Internet

\subsection{Types and Amount of Information Obtained from the Internet}

The most $(98,46.0 \%)$ explored information type by the participants was update on professional issues, followed by information on continuing professional education for capacity building $(71,33.3 \%)$, while about one-quarter (52,
$24.4 \%)$ of them searched for academic information. Many participants $(118,55.4 \%)$ attested that they found very much of the information being sought.

\subsection{Barriers to Computer Use}

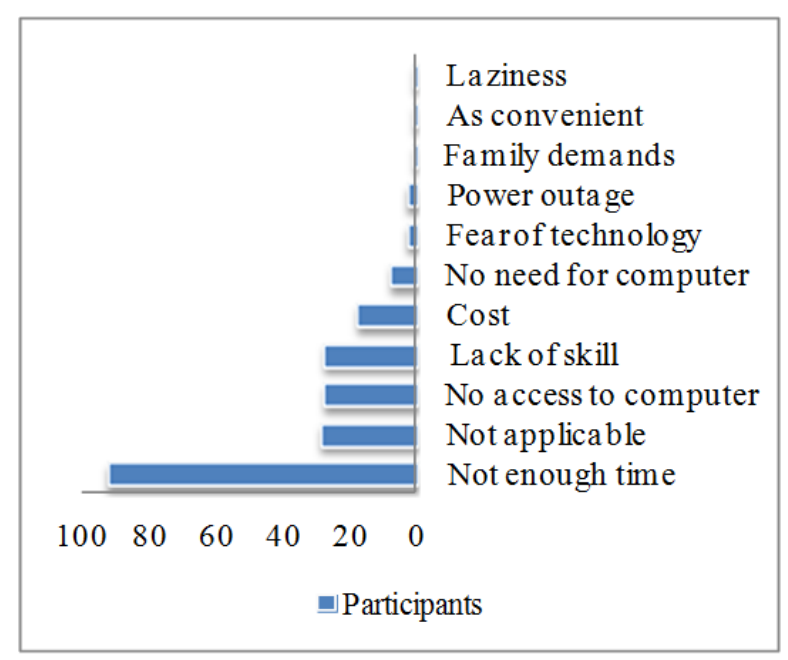

Figure 2. Barriers to computer use

Various barriers associated with the use of computer and the Internet is presented in Fig. 2 above. Chief among the barriers was complaint about time constraints (93, 43.7\%), followed distantly by lack of access to computer $(28,13.1 \%)$ and lack of computing skills $(28,13.1 \%)$. Good to note that one participant $(0.5 \%)$ ascribed failure to use these technologies to laziness.

\subsection{Email and Quest for Continuing ICT Training}

Email is a method of exchanging digital messages from a sender to a receiver. It is noteworthy that the majority (123, $57.7 \%$ ) of participants in this study regularly used e-mail whereas; a significant number $(37,17.4 \%)$ had never used it before. Most participants $(194,91.1 \%)$ indicated interest in further training in the use of e-mail resources while an overwhelming majority signified quest for further training in computer $(204,95.8 \%)$ and the Internet (199, 93.4\%). Notably, all HIM students (40,100\%) indicated quest for such training while a negligible but discernible portion of nurses $(3,2.9 \%)$ and doctors $(1,2.1 \%)$ refuted further training in computer and the Internet.

\section{Discussion}

The emerging digitization and globalization has the potentials to speed up the transformation of the current healthcare systems and revolutionize the provider-consumer relationship between healthcare providers, their patients and the public. Traditionally, there is an apparent vicious cycle in healthcare, portending low health literacy among the consumers, inaccessibility to emerging technologies among both the consumers and the providers and in effect, poor health outcomes. However, if ICTs which include the use of 
computer and the Internet are actively deployed, the vicious cycle will be broken [14] and healthcare delivery becomes improved and the public health is better for it. Relatively, our study found that the majority of the participants had used these technologies with reasonable experience as 53\% and $37 \%$ of them had used computer and the Internet for more than three years respectively. Our study coincides with other studies $[22,21,27,20,33,36,1$ and 6] that have earlier reported good utilization of computer and the Internet. It however established improvement on studies such as [9, 37, $25,38,39,4$ and 40] with low utilization of computer and the Internet.

Major factors that contributed to the way healthcare professionals in this study utilized computer and the Internet were profession, previous exposure to the technologies and salary levels at times. For instance, $81 \%$ of doctors had used computer for more than three years and these doctors alone constituted $56 \%$ of those participants who had used the Internet for over seven years. Statistically, profession had significance $(p=0.00)$ on computer and Internet use. Likewise, previous exposure to the technologies had statistical significance on recurrent use as most $(74.5 \%)$ of those who had used computer, and half $(50.0 \%)$ of those who had used the Internet for seven years; used both computer and the Internet daily in the recent times. Equally, salary level was contributory to utilization of computer and the Internet with $(p=0.00)$ and $(p=0.024)$ respectively. Hypothetically, doctors' high rate of health information use, their high income and their leadership roles in the healthcare system could possibly be having an influence on the way they use computer and the Internet relative to other healthcare providers, including HIM professionals charged with the management of healthcare information systems. For instance, Bello et al [25] reported that doctors had higher possession of computer possibly due to their perceived need and relative ease of affordability. Conversely, Bello et al [25] established that training opportunities available to HIM professionals due to their obligations to manage health information systems might not translate into better knowledge and good utilization habits in computer and the Internet. Our study confirmed the affordability effects as salary level had statistical significance $(p=.00)$ on computer and Internet use. Furthermore, Gour \& Srivastava [41] reported that of all groups of healthcare providers in a study, doctors and nurses were well indulged in the use of computer.

Healthcare providers' search for information is unlimited and various reasons motivated the types of information being sought on the Internet. As such, Cullen [24] opined that there is need for better provision of evidence-based sources and that the Internet could be a valuable medium for such. Similarly, Glaser et al [42] has proven that the use of the Internet and computing technologies such as tablet interface had increased the accuracy and speed for data extraction compared to paper. Most often, professional updates (46\%), updates on continuing professional education $(33.3 \%)$ and updates on emerging diseases (28.6\%), motivated participants in our study to use the Internet. Whereas, they hardly $(0.5 \%)$ search the Internet for entertainment reasons and the majority $(55.4 \%)$ demonstrated that they were able to obtain very much of such information. Foremost online database deployed by the participants was Google Scholar $(72.3 \%)$, the most used (65.7\%) social media was Facebook, and cell phone was the most (70.0\%) deployed platform for accessing the Internet. Though, Dorsch [43] reported low utilization of online databases, our findings tally with a report from Pennsylvania [44] where two-third of the participants used the Internet for health-related purposes. In addition, several studies [25, 27, 33, 45, 30 and 26] also corroborated the reasons adduced in our study especially, as it relates to professional discoveries and patient care. Tai et al [29] submitted that such information had sharpened healthcare providers' thinking and made them more efficient. Adinku [46] also reported that cellphone was mostly used for Internet search in Ghana. However, the case was not the same in a report by Ajuwon [45] where MEDLINE/Pubmed was the most frequently accessed database and cyber cafés top the list of preferred platforms.

Much as the healthcare providers in this study would have explored the benefits of the Internet, they were constrained majorly $(43.7 \%)$ by shortage of time. It is good to note that this major barrier was followed by reported inadequacy in both access and technical knowhow (13.1\% each). Time constraints has been reported by Konrad et al [32] and Dorsch [43] as major factor limiting how much healthcare providers can do both at care provision and on Internet use. Coit [47] also reported that this constraint was triggered by workload of healthcare providers and Mechanic [48] said that it could be reallocated to make more meaningful communication through the use of the Internet. However, Yeung et al [30] refuted time constraints as an inhibiting factor to care provision, as it was reported to have less influence on Internet use among participants from developing nations relative to their contemporaries in the developed nations. Access to healthcare information has become a key international development issue [49] and improved proficiency in the use of computer and the Internet had been recommended [30] as one way to improve access to invaluable health information among healthcare professionals. It is quiet alluring that this current study reveals general quest for further training in the use of computer $(95.8 \%)$, the Internet (93.4\%) and specifically, e-mail (91.1\%) with all the trainees $(100 \%)$ in the study seeking for further training. The findings on further training in computer and the Internet correspond with previous studies such as Adeleke et al [16] where participants wanted more training in electronic data analysis; Gour \& Srivasta [41] with demands on provision for computer training and Cullen [24] with training in the identification, use, and application of evidence in practice. Other corroborating reports are Salako \& Tiamiyu [50] on how to enhance efficiency in academic pursuance; Yeung [30] on benefits of technology-enabled training; Ajayi [31] on the introduction of health informatics and Chan et al [51] reported that a group of primary care nurses with consensus required training with a view to improving their computer 
use.

\subsection{Study Limitations}

The study design did not make a distinction between general Google search and specific search of Google Scholar which is rather more of research and academic platform. This might have informed the overwhelming response on Google Scholar as a search engine of interest in the study. In any case, only a few groups of healthcare providers are recruited into the study. As such, this may not hold the impetus for generalization of utilization habits of computer and the Internet among the diverse healthcare providers' groups.

\section{Conclusion}

Healthcare providers and trainees at Federal Medical Centre, Bida have good disposition towards computer and Internet use especially for the enhancement of their professional practice and improvement of patient care quality. They overwhelmingly sought for further training in the use of computer and the Internet with a view to boosting their sources of information for better practice and improved public health. Any effort at enriching their sources of information and enhancing their usability of these technologies would be worthwhile.

\section{Recommendations}

i Preparatory to better electronic healthcare environments which tend to evolve an improved healthcare quality, it is very important that the hospital and other healthcare facilities in Nigeria organize specific and intensive ICT training for their employees and make necessary infrastructures available for the implementations.

ii Specifically, there is need to organize continuing professional education, training and retraining in ICT for health information management professionals in order to assume their leadership roles in healthcare information systems in Nigeria. This is especially central as the country adopts electronic health records with a view to evolving harmonized health data management.

iii On a general note, there is a need for advocacy on the need to embrace health IT among all healthcare professionals in Nigeria.

\section{Acknowledgement}

The sheer assistance on data collection as rendered by Messrs. AA Adebisi, LM Ogundiran, SA Omokanye, OO AbdulGhaney and OA Abodunrin of the Department of Health Information, Federal Medical Centre, Bida is duly acknowledged. Mr. OP Williams of the Department of Administration is genuinely acknowledged for his efforts on grammar. Likewise, the authors wish to thank the one hundred and ninety two staff of Federal Medical Centre, Bida and the forty HIM students from the Niger State College of
Health Technology, Minna who participated in the study.

\section{Appendix I}

Department of Health Information

Federal Medical Centre, Bida

$17^{\text {th }}$ June 2013

Dear Sir/Madam

Informed Consent and Permission to Partake in a Study

A scientific study on utilization of the Internet among tertiary healthcare providers in Bida as well as health information management (HIM) students from Minna is ongoing and we wish you kindly respond to the questions below to your best understanding of the state of affairs. Be assured of utmost anonymity and confidentiality of any information supplied in the course of this study. Moreover, the primary intention is to use the findings for academic purposes and to improve healthcare practice to our teeming clients. Note that, participation is entirely voluntary and your decision to opt out is of no consequence. If there arise any question regarding your participation in this study, kindly direct it to:

Adeleke, IT of the Dept of Health Information, Federal Medical Centre, Bida

E-mail: ibratadeleke_aliseyin@yahoo.com Mobile: +234 8034229146,8056503465

If you are pleased to participate, kindly sign the consent column below:

Signature with date

Thank you for the anticipated cooperation.

\section{Questionnaire on Computer and Internet Use among Tertiary Healthcare Providers and Trainees in Bida, Nigeria}

\section{Section A: Basic Demography}

A1 Sex

a. Male

b. Female

A2 Age in years

a. Less than 21

b. 21 to 30

c. 31 to 40

d. 41 to 50

e. 51 to 60

f. Above 60

A3 Profession

a. Nursing

b. Medicine \& Surgery

c. Health Information Management (HIM)

d. HIM Student

A4 CONHESS Level or equivalent
a. 13 to 15
b. 9 to 12
c. 6 to 8
d. HIM Student 


\section{Section B: Computer Use}

B1 For how long have you been using computer?
a. Less than 6 months
b. 6 to 12 months
c. 1 to 3 years
d. 4 to 6 years
e. 7 or more years
f. I have never used a computer

B2 In the last month, how many times did you use a computer?
a. Everyday
b. More than once a week
c. Once a week
d. Less than once a week
e. Don't know
f. I have never used computer

B3 Which of the following barriers keep you from using computer often? (Tick as appropriate)
a. Cost
b. No access to computer
c. Lack of skills or training
d. Fear of technology
e. No need
f. Not enough time
g. Disability
h. Don't know
i. Other (Pleases specify

B4 Would you be interested in participating in a workshop to learn more about how to use computer?
a. Yes
b. No
c. Don't know

\section{Section C: Use of the Internet}

C1 For how long have you been using the internet?

a. Less than 6 months?

b. 6 to 12 months?

c. 1 to 3 years?

d. 4 to 6 years?

e. 7 or more years?

f. I have never used the internet

C2 In the last month, how many times did you use the internet?

a. Everyday

b. More than once a week

c. Once a week

d. Less than once a week

e. Don't know

f. I have never used the internet

C3 Which of the following barriers keep you from using the internet often? (Tick as appropriate)
a. Cost
b. No access to the internet
c. Lack of skills or training
d. Fear of technology
e. No need
f. Not enough time
g. Disability
h. Don't know
i. Other (Please specify
C4 What amount of your professional/ health information is available on the internet?
a. Very little
b. A little
c. Some
d. Very much
e. Don't know

C5 Which of the following platforms do you use most in accessing the internet?
a. Café computer systems
b. Cell phone
c. Office internet services
d. Other (Please specify

C6 Would you be interested in participating in a workshop to learn more about how to use the internet?
a. Yes
b. No
c. Don't know

Section D: Type, Usage Rate and Source of Information on the Internet

D1 What type of information do you seek on the internet? Tick as appropriate.

a. Health information on emerging diseases

b. Drugs and medication

c. Professional updates

d. Lifestyle (i.e. diet, nutrition, exercise, prevention and so on)

e. Updates on football and other athletics

f. Updates on continuing professional development education

g. Updates on general health information for patients' care

h. Purely academic issues

i. None

j. Other (Specify

D2 Which of the following search engines/online database have you ever used to obtain professional or academic information? Tick as appropriate.
a. HINARI
b. Medline/Pubmed
c. AJOL
d. Google Scholar
e. Other (Specify

D3 Which of the following social media have you ever used to communicate professional or health information? Tick as appropriate.
a. Twitter
b. LinkedIn
c. YahooGroup
d. Facebook
e. Other (Specify )

D4 In the last month, how often did you communicate using e-mail? 
a. Everyday

b. More than once a week

c. Once a week

d. Less than once a week

e. Don't know

f. I have never used the e-mail

D5 Would you find it useful sharing health information and professional news with colleagues using e-mail?

a. Yes

b. No

c. Don't know

D6 Would you be interested in participating in a workshop to learn more about how to use the search engines and e-mail?

a. Yes

b. No

c. Don't know

\section{References}

[1] I. A. Asangansi, O. O. Adejoro, O. Farri and O. Makinde. Computer use among doctors in Africa: survey of trainees in a Nigerian teaching hospital. Journal of Health Informatics in Developing Countries. 2008;2(1): 10-14.

[2] B. Chaudhry, J. Wang, W. Shinyi, et al. Systematic review: impact of health information technology on quality, efficiency and costs of medical care. Annals of Internal Medicine. 2006;144:742-752.

[3] B. Wheatley. Transforming care delivery through health information technology. Permanente Journal. 2013;17(1):8186 doi:10.7812/TPP/12-030. PMCID: PMC3627785.

[4] N. Ameh, T. S. Kene, E. A. Ameh. Computer knowledge among clinical year medical students in a resource poor setting. African Health Sciences. 2008;8(1):40-43.

[5] F. O. Olalude. Utilization of internet sources for research by information professionals in sub-Saharan Africa. African Journal of Library, Archives \& Information Science. 2007;17(1):53-58.

[6] M. Trivedi, A. Joshi. Computer and internet use by healthcare professionals in a rural medical college in India. Library Philosophy and Practice. 2008:1-4.

[7] G. Eysenbach. Medicine 2.0: Social networking, collaboration, participation, apomediation and openness. Journal of Medical Internet Research. 2008;10(3):e22.

[8] R. Hurling, M. Catt, M. D. Boni, et al. Using internet and mobile phone technology to deliver an automated physical activity program: Randomized trial. Journal of Medical Internet Research. 2007; 9(2): e7.

[9] R. Schoenberg, C. Safran. Internet based repository of medical records that retains patient confidentiality. British Medical Journal. 2000;21(7270): 1199-1203. PMCID: PMC1118958.

[10] I. T. Adeleke, A. O. Adekanye, S. A. Adefemi, et al. Knowledge, attitudes and practice of confidentiality of patients' health records among healthcare professionals at Federal Medical Centre, Bida. Nigerian Journal of Medicine.
$2011 ; 20(2): 228-235$.

[11] J. D. Halamka, P. Szolovits, D. Rind, C. Safran. A www implementation of national recommendations for protecting electronic health information. Journal of American Medical Informatics Association. 1997;4:458-464. doi:10.1136/jamia.1997.0040458.

[12] E. H. Shortliffe, K. W. Goodman, R. A. Miller. Ethics and health informatics user, standard and outcomes. In Shortliffe EH (ed). Medical informatics: Computer applications in healthcare. $2^{\text {nd }}$ ed chapter 7 2008.New York: Springer-Verlag.

[13] E. J. Schweitzer. Reconciliation of the cloud computing model with US Federal electronic health record regulations. Journal of American Medical Informatics Association. 2012; 19:161-165. doi:10.1136/amiajnl-2011-000162.

[14] G. Eysenbach. Consumer health informatics. British Medical Journal. 2000;320(7251):1713-1716.

[15] R. Wilson. Using computers in health information systems. Available at: www.whqlibdoc.who.int/publications/2000/9241561998_(chp 11).pdf Accessed on 23rd November 2013.

[16] I. T. Adeleke, A. H. Lawal, R. A. Adio, A. A. Adebisi. Information technology skills and training needs of health information management professionals in Nigeria: a nationwide study. Health Information Management Journal, 2014. doi.org/10.12826/18333575.2014.0002.Adeleke.

[17] I. T. Adeleke, A. O. Adekanye, K. A. Onawola, et al. Data quality assessment in healthcare: a 365-day chart review of inpatients' health records at a Nigerian tertiary hospital. Journal of American Medical Informatics Association. 2012;19(6):1039-42. doi:10.1136/amiajnl-2012-000823.

[18] M. C. Gibbons. Use of health information technology among racial and ethnic underserved communities. Perspectives in Health Information Management. 2011; 8(1).

[19] T. Kind, Z. Huan, D. Farr, K. Pomerantz. Internet and computer access and use for health information in an underserved community. Ambulatory Pediatric. 2005;5(2):117-121. PMID: 15780014.

[20] N. A. Ajayi. Information seeking by nurses in the Obafemi Awolowo University Teaching Hospital, Nigeria. Information Development. 2005;21(2):121-127. doi: $10.1177 / 0266666905054506$.

[21] S. C. Inamdar, S. B. Rotti. Computer use among medical students in an institution in southern. India. National Medical Journal of India. 2004;17:8-10.

[22] N. A. Jadoon, M. F. Zahid, F. Mansoorulhaq, et al. Evaluation of Internet access and utilization by medical students in Lahore, Pakistan. BMC Medical Informatics and Decision Making. 2011; 11:37. www.biomedcentral.com/14726947/11/37.

[23] K. Ramos, R. Linscheid, S. Schafer. Real-time information seeking behaviour of resident physicians. Point-of-care Medical Information. 2003;35(4): 257-260.

[24] R. J. Cullen. In search of evidence: family practitioners' use of the internet for clinical information. Journal of Medical Library Association. 2002; 90(4): 370-379. 
[25] I. S. Bello, F. A. Arogundade, A. A. Sanusi, I. T. Ezeoma, E. A Abioye-Kuteyi, A. Akinsola. Knowledge and utilization of information technology among healthcare professionals and students in Ile-Ife, Nigeria: A case study of a University Teaching Hospital. Journal of Medical Internet Research. 2004;6(4): e45.

[26] E. E. Baro, L. Ebhomeya. Information needs and seeking behaviours of nurses: a survey of two hospitals in Bayelsa State, Nigeria. Health Education. 2013;113(3):183-195.

[27] N. L. Bennett, L. L. Casesbeer, R. E. Kristofco, S. M. Strasser. Physicians' internet information-seeking behaviours. The Journal of Continuing Education in the Health Professions. 2004;24: 31-38.

[28] A. I. Gonzalez-Gonzalez, M. Dawes, J. Sanchez-Mateos, et al). Information needs and information seeking behaviour of primary care physicians. Annals of Family Medicine. 2007;5(4):345-352.

[29] S. S. Tai, C. Donegan, C, I. Nazareth. Computers in general practice and the consultation: the health professionals' views. Health Information Management Journal. 2000;6: 27-31.

[30] E. Yeung, R. Balogh, D. Cole, D. Jakovic, M. D. Landry. Internet use among community-based rehabilitation workers in Herzegovina: A cross-sectional survey. Physiotherapy Canada. 2011;63(4): 445-452.

[31] N. A. Ajayi. Impact of health informatics on nurses' computer skills and the role of the library. Electronic Library, The. 2013;31(2):157 - 166 .

[32] T. R. Konrad, C. L. Link, R. J. Shackelton, et al. It's about time: physicians' perceptions of time constraints in primary care medical practice in three national healthcare systems. Medical Care. 2010;48(2): 95-100. doi:10.1097/MLR.0b013e3181c12e6a PMCID:PMC3621071. NIHMSID: NIHMS454710.

[33] N. L. Bennett, L. L. Casesbeer, R. Kristofio, B. C. Collins. Family physicians' information seeking behaviours: a survey comparison with other specialties. BMC Medical Informatics and Decision Making. 2005;5:9.

[34] C. Watts, I. Ibegbulam. Access to electronic healthcare information resources in developing countries: experiences from the Medical Library, College of Medicine, University of Nigeria. IFLA Journal. 2006;32(1): 54-61. doi:10:117/0340035206063.

[35] C. M. T. Nweze. Health Information needs of first-year students in Nigerian universities: a case study of Obafemi Awolowo University, Ile-Ife. Journal of Hospital Librarianship. 2008;8(2): 201-210 doi: 10.1080/15323260801928522.

[36] M. McKnight. The information seeking on-duty critical care nurses: evidence from participant observation and in-context interviews. Journal of Medical Library Association. 2006;94(2): 145-151.

[37] G. A. Ajuwon, G.A. Computer and internet use by first year clinical and nursing students in a Nigerian teaching hospital. BMC Medical Informatics and Decision Making. 2003;3:10.
[38] M. Samuel, J. C. Coombes, J. J. Miranda, R. Melvin, E. J. W. Young, P. Azarmina. Assessing computer skills in Tanzanian medical students: an elective experience. BMC Public Health. 2004;4:37.

[39] G. A. Ajuwon and L. L. Rhine. The level of internet access and ICT training for health information professionals in subSaharan Africa. Health Information Library Journal. 2008;25(3):175-185.

[40] I. T. Adeleke, A. O. Adekanye, A. D. Jibril, F. F. Danmallam, H. E. Inyinbor, S. A. Omokanye. Research knowledge and behaviour of health workers at Federal Medical Centre, Bida: a task before learned mentors. El Mednifico Journal. 2014;2:2.

[41] N. Gour and D. Srivastava. Knowledge of computer among healthcare professionals of India: a key toward e-Health. Telemedicine and e-Health. 2010;16(9): 957-962. doi:10.1089/tmj.2010.0049.

[42] D. Glaser, S. Jain, and P. Kortum. Benefits of a physicianfacing tablet presentation of patient symptom data: comparing paper and electronic formats. BMC Medical Informatics and Decision Making. 2013;13:99. doi: 10.1186/1472- 6947-13-99.

[43] J. L. Dorsch. Information needs of rural health professionals: a review of literature. Bulletin of Medical Library Association. 2000;88(4): 346-354.

[44] S. G. Park, D. G. Nazarian and C. K. Lim. Adoption of information technology by physicians. Clinical Orthopaedic Related Research. 2004;421:107-111.

[45] G. A. Ajuwon. Use of the Internet for health information by physicians for patient care in a teaching hospital in Ibadan, Nigeria. Biomedical Digital Libraries. 2006;3:12. doi:10.1186/1742-5581-3-12.

[46] S. Adinku. Towards disaster preparedness and recovery planning procedures for libraries. A survey of staff and users of the Balme Library, University of Ghana. African Journal of Library, Archives \& Information Science. 2005;15(1): 75-79.

[47] M. H. Coit, J. T. Katz and G. T. McMahon. The effect of workload reduction on the quality of residents' discharge summaries. Journal of General Internal Medicine. 2011;26(1): $28-32$.

[48] D. Mechanic. How should hamsters run? Some observations about sufficient patient time in primary care. British Medical Journal. 2001;4;323(7307): 266-268. PMCID: PMC35349.

[49] F. Godlee, N. Pakenham-Walsh, D. Ncayiyana, B. Cohen and A. Packer. Can we achieve health information for all by 2015 ? Lancet. 2004;364: 295-300.

[50] O. A. Salako and M. A. Tiamiyu. Use of search engines for research by postgraduate students of the University of Ibadan, Nigeria. African Journal of Library, Archives \& Information Science. 2007;17(2): 103-115.

[51] T. Chan T, S. Brew and S. D. Lusignan. Community nursing needs more silver surfers: a questionnaire survey of primary care nurses' use of information technology. BMC Nursing.2004;3:4. doi: 10.1186/1472-6955-3-4. 